\title{
Research on Optimization of Mining Substitution in Wangzhuang Mine Based on System Dynamics
}

\author{
Shuheng Zhong $\mathbb{D},{ }^{1}$ Yuchen Guo $\mathbb{D}^{1},{ }^{1}$ Yanjiao $\mathrm{Li} \mathbb{D}{ }^{1},{ }^{1}$ and Ming Yang $\mathbb{D}^{2}$ \\ ${ }^{1}$ School of Energy and Mining, China University of Mining and Technology (Beijing), Beijing 10083, China \\ ${ }^{2}$ School of Information Network Security, People's Public Security University of China, Beijing 10083, China \\ Correspondence should be addressed to Yanjiao Li; 542805524@qq.com
}

Received 3 June 2021; Accepted 25 August 2021; Published 10 September 2021

Academic Editor: Roberto Nascimbene

Copyright ( 2021 Shuheng Zhong et al. This is an open access article distributed under the Creative Commons Attribution License, which permits unrestricted use, distribution, and reproduction in any medium, provided the original work is properly cited.

\begin{abstract}
The unbalanced mining replacement is a major problem restricting efficient mining. The optimization of mining replacement process can achieve perfect coordination of mining face and tunneling in time and ensure the efficient production of mine to the greatest extent. Based on this, this paper takes Wangzhuang Mine as the research background, applies system dynamics to mining replacement research, builds the Wangzhuang Mine mining-driving system simulation model, and uses this model to dynamically simulate the working face 9102 and its replaced heading face 7106. The research has found that there is an imbalance in the replacement between the two working faces, and the replacement process can be optimized by advancing the driving period or increasing the driving team to work in parallel at the appropriate time point, so as to meet the normal demand of mining replacement and provide guidance for the mining plan arrangement of other similar working faces.
\end{abstract}

\section{Introduction}

With the development of big data technology and mechanization and intelligence, the advancing speed of the working face has become faster and faster. Although the advancing speed of heading face has been improved, it still lags behind the working face, which causes the imbalance of mining replacement and affects the production efficiency of the mine. Therefore, in order to improve the coal output and to ensure the high efficiency of mine production, it is necessary to optimize the mining process [1-3]. Aiming at the problem that the excavation lags behind the mining, the main factors restricting the speed of roadway driving were summarized and the future development direction was proposed [4-6]. Some scholars have put forward prospects and suggestions for the improvement of driving speed from the aspects of tunneling technology and equipment [7-9]. Some scholars have established an intelligent decision system for mining replacement with the help of computers [10-12].

References [4-6] only put forward the problem of comprehensive roadway excavation in our country, indicate the future development direction of tunneling, or just point out the overall process cycle optimization. References [7-9] explain the current situation of rapid tunneling technology, discuss key technical issues, or quickly optimize tunneling technology through theoretical calculation. References [10-12] abandon the traditional manual planning and gradually use the cross-platform and versatile software in the computer to prepare the mining succession planning system. The above research is committed to explore how to improve the speed of excavation to cooperate with mining face completing the excavation replacement both from the perspective of technology and intelligent decision and alleviate the imbalance problem of excavation replacement to a certain extent. However, it is rarely considered from the perspective of mining replacement optimization. The optimization of mining and driving replacement is to arrange the driving tasks reasonably in terms of time to meet the replacement demand and avoid the waste of resources, which is the prerequisite for the realization of intelligent mining. Based on this, this paper applies system dynamics to the study of optimization of mining and driving replacement to improve mine production efficiency better. 


\section{Model Building}

System dynamics is a discipline which could study the dynamic development process of complex systems and uses computer simulation technology to simulate the dynamic development process of the system based on feedback control theory [13-15]. The modeling process mainly includes two aspects, model building (system boundary determination, causality analysis, and structural flow diagram drawing) and simulation (parameter setting, simulation analysis, countermeasures, and suggestions) $[16,17]$.

2.1. System Boundary Determination. There are two mining levels of +630 and +540 in Wangzhuang Mine. The mining coal seam is No. 3 coal seam. Working plane which has been replaced recently includes 9102 mining face, 7106 ventilating roadway, and 7106 transportation roadway. The 9102 mining face is located in the 91 mining area. In the working face, there are 3 faults and 2 collapse columns (fault F304 $H=5.0 \mathrm{~m} \angle 65^{\circ}$, fault F317 $H=8.5 \mathrm{~m} \angle 40^{\circ}$, fault $\mathrm{F} 318$ $H=1.4 \mathrm{~m} \angle 40^{\circ}$, collapse column H51, and collapse column $\mathrm{X} 14)$. The 7106 working face passes through five anomaly areas. They are the comprehensive response of coal seam thinning, crack development, concealed geological structure, or coal structure abnormality. From the perspective of current situation of the mine production, mining replacement is unbalanced. Through the analysis, the factors affecting the driving speed of heading face 7106 and the advancing speed of working face 9102 are summarized into the following six aspects, as shown in Table 1. In the table, " $\sqrt{ }$ " means that it will affect the system, and " $\times$ " means that it will not affect the system.

2.2. Causality Analysis. Causality analysis can effectively analyze the relationship between various factors in the system [18, 19]. The causality diagram of the excavating system is based on the coal mining system and the driving system, illustrating the influence of various factors on the rapid driving of the roadway, the advancing speed of the mining face, and the interaction between the two systems. The factors that affect the excavating system mainly include geological structure, operating environment, mechanical equipment, regular circulation level, etc. The influence of each factor on the system is shown in Figure 1. The causal relationship between each factor is represented by a causal chain composed of causal arrows with positive (+) and negative (-) signs. Taking "Airflow Gas Concentration of Heading Face" as an example, the Airflow Gas Concentration of Driving Face $\uparrow \longrightarrow(-)$ Gas Level of Driving Face $\downarrow \longrightarrow(-)$ Operating Environment Level of Driving Face $\downarrow \longrightarrow(-)$ Tunneling footage $\downarrow \longrightarrow(-)$ Driving distance of Driving Face $\downarrow$.

2.3. System Structure Flow Diagram. Based on the analysis of the causality of the excavating system, the structure flow diagram of the excavating system is drawn with Vensim software, as shown in Figure 2. The structure flow diagram contains two rate variables: the driving speed and the advancing speed of the working face, and two state variables (cumulative quantities): the driving length and the advancing distance of the working face.

\section{Simulation}

The above established model is applied to the 9102 working face and 7106 heading face of Wangzhuang Mine. The 9102 working face has a total length of 3,500 meters, the actual mining distance is 2450 meters, and the mining time is 24 months. The total length of the 7106 ventilation roadway and transport roadway lane is 2500 meters, and the driving time is 27 months. Therefore, the system simulation time is set as 27 months and simulation step length is 1 month.

\subsection{Parameter Setting}

3.1.1. Weight Determination. The weight values of each index are determined by the group AHP method except the two indexes of advanced roadway support level and the moving level of two sides of roadway, which were given by experts. The weight results are shown in Table 2.

3.1.2. Basic Parameter Setting. The basic parameters mainly include the distance from the tunneling face to the geological structure zone, the failure rate of the tunneling face mechanical equipment, the gas concentration of the return air flow from the heading face, the distance from the mining face to the geological structure zone, the normal circulation rate of the mining face, etc.

3.1.3. Assignment of Auxiliary Variables. The level of each influencing factor changes as the value of the factor changes. This paper uses table function to express the relationship between the level and the actual value of the influencing factors. The level of influencing factors was quantified with $40 \sim 100$ scores. The influence degree is represented by the promotion or weakening effect on the numerical value of the affected factor, whose value may be greater than or less than 1. Considering the research results of many scholars, the paper defines the range of influence to be between 0.5 and $1.5[20]$.

\subsection{Simulation Analysis}

3.2.1. Model Checking. Vensim software has its own "check model" function, which can check the consistency of model units. The simulation model in this paper runs well, and the consistency of the model units is verified by the "check model" function. After running the model, it can be obtained that the simulated output value of driving length is $2,441.765$ meters, and the error rate is $-2.33 \%$ compared with the actual value of 2500 meters. Compared with the actual value of 2450 meters, the simulated output value of the advance distance of the coal mining face is 2526.87 meters, and the error rate is $+3.14 \%$. The absolute error value of both is less 
TABLE 1: Key influencing factors of mining system.

\begin{tabular}{|c|c|c|c|}
\hline The key factors & Detailed index & $\begin{array}{l}\text { Driving } \\
\text { system }\end{array}$ & $\begin{array}{c}\text { Coal mining } \\
\text { system }\end{array}$ \\
\hline Geological structure level & Distance of geological structural zone $(\mathrm{m})$ & $\sqrt{ }$ & $\sqrt{ }$ \\
\hline \multirow{2}{*}{ Mine pressure level of underground roadway } & Advance support distance of roadway $(\mathrm{m})$ & $x$ & $\sqrt{ }$ \\
\hline & Two-sided displacement $(\mathrm{mm})$ & $\times$ & $\sqrt{ }$ \\
\hline \multirow{5}{*}{ Working environment level } & Water inflow per unit time at mining face $\left(\mathrm{m}^{3} / \mathrm{h}\right)$ & $\sqrt{ }$ & $\sqrt{ }$ \\
\hline & Roof crushing degree & $\sqrt{ }$ & $\sqrt{ }$ \\
\hline & Roof falling capacity (mm) & $\sqrt{ }$ & $\sqrt{ }$ \\
\hline & Roof subsidence rate $(\mathrm{mm} / \mathrm{min})$ & $\sqrt{ }$ & $\sqrt{ }$ \\
\hline & Return air flow gas concentration at the mining face (\%) & $\sqrt{ }$ & $\sqrt{ }$ \\
\hline Regular circulation level & Normal circulation rate $(\%)$ & $\sqrt{ }$ & $\sqrt{ }$ \\
\hline Mechanical and electrical equipment failure level & Electromechanical equipment accident rate (\%) & $\sqrt{ }$ & $\sqrt{ }$ \\
\hline Power on level & Operating rate $(\%)$ & $\sqrt{ }$ & $\sqrt{ }$ \\
\hline
\end{tabular}

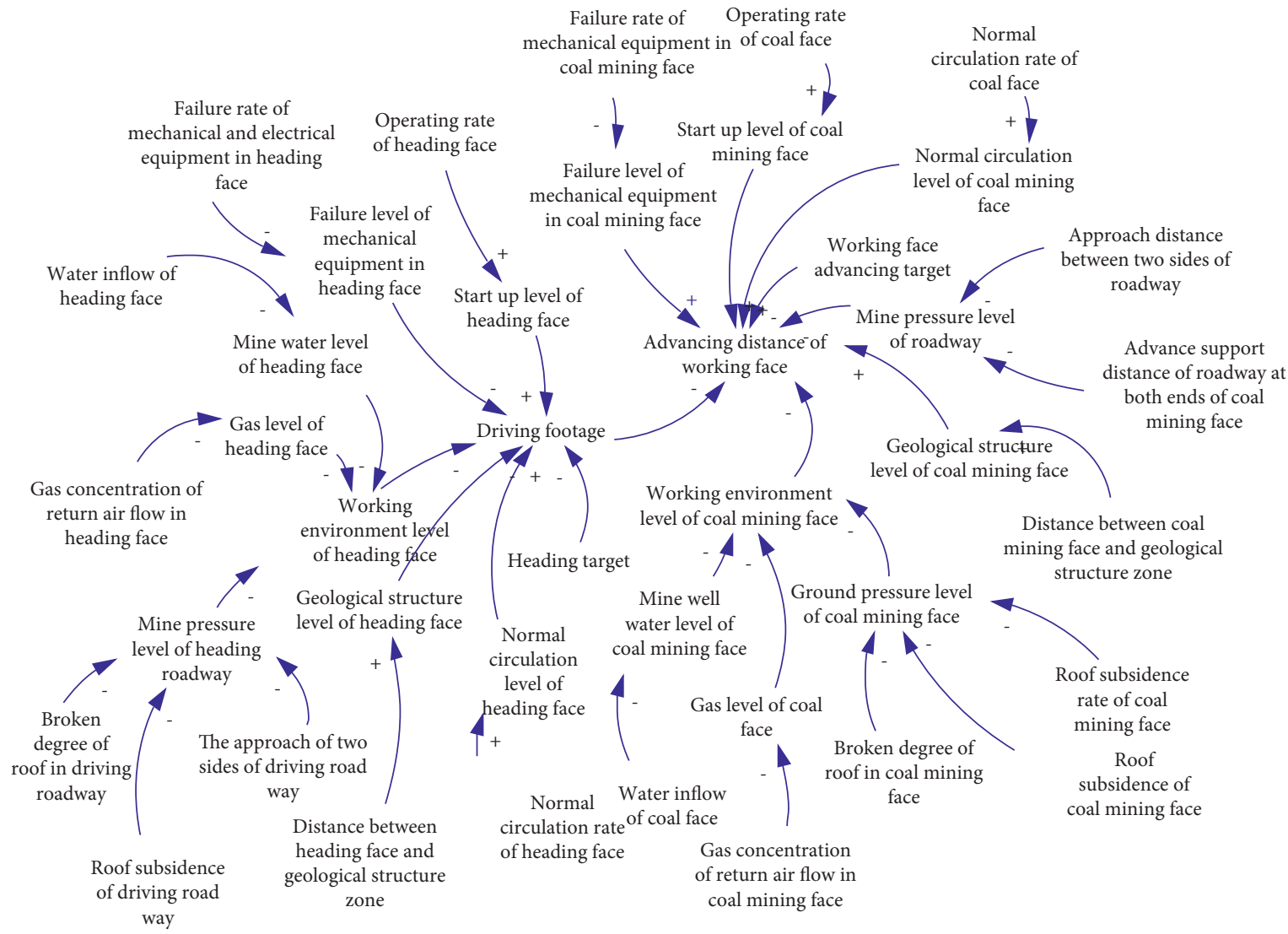

Figure 1: Causality diagram of mining-driving system.

than $5 \%$, indicating that the model has a good effect and is qualified.

\subsubsection{Analysis of Simulation Results}

(1) The relationship between the level of each influencing factor and the driving speed is shown in Figures 3(a) and 3(b). It can be seen from the figure that all influencing factors have an impact on the driving speed. The level of geological structure reached its lowest point in the 5th and 19th months, and the level of other influencing factors reached their lowest in the 6th and 20th months. Driving speed also reached its lowest point in the 6 th and 20th months correspondingly. The curve trend of the driving speed was roughly the same as the horizontal curve trend of each influencing factor.

(2) The relationship between the level of each influencing factor and the advancing speed of the working face is shown in Figures 4(a) and 4(b). It can be seen from the figure that various factors have an impact on the advancing speed of the 


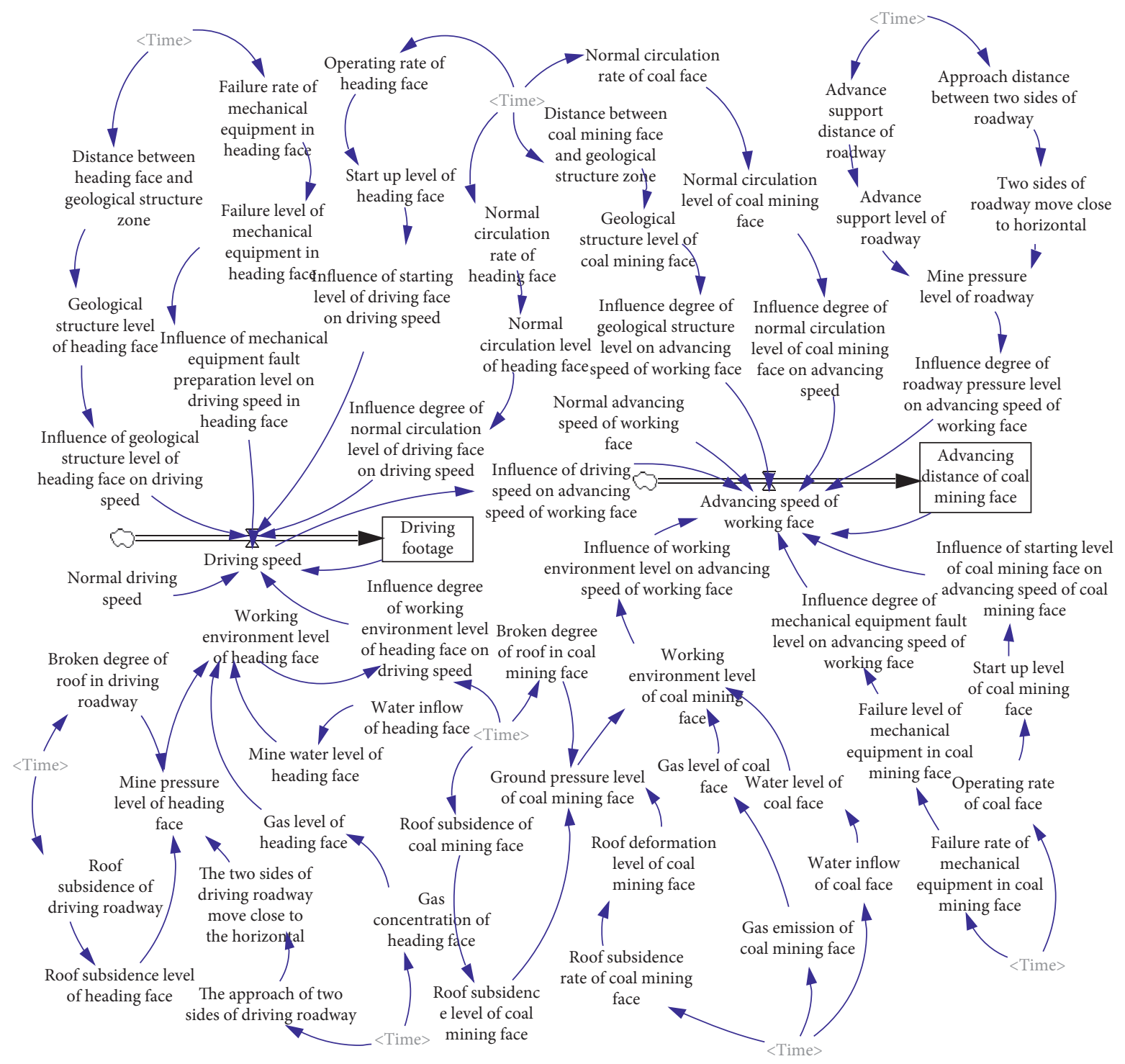

FIgURE 2: Structure flow diagram of mining-driving system.

working face. The level of geological structure remained at a relatively low level from 4th to 9th and 16th to 18th months, while other factors also fluctuated at a low level during this period. The driving speed reached its lowest point in the 6th and 17 th months, and the trend of the tunneling speed curve of the working face was roughly consistent with that of the horizontal curve of the influencing factors.

(3) The simulation results of the mining-driving system are shown in Figures 5(a)-5(d). From Figure 5(a), it can be seen that the advancing speed of the 9102 working face has been significantly slower since April. Also, for nearly 5 months thereafter, its speed remained at a low level, rose in the 11th month, and then significantly decreased in the 17th month. But the duration is short. It returned to above the normal advancing speed in the 20th month. The main reason is that the 9102 working face was getting closer and closer to the F304 fault in the fourth month, and the span of F304 is 490 meters. Therefore, under the influence of the fault, the driving speed remained at a low state for a long time. In the 17th month, the working face encountered collapse columns H51 and X14 one after another. The two collapse columns were adjacent and the span was relatively small. Therefore, the impact time on the speed was relatively short. Correspondingly, the working face advance distance curve slowed down as its speed decreased. It can be seen from Figure 5(b) that the driving speed of the heading face decreased significantly in the 4th month, reached the lowest point in the 6th month, then decreased significantly in the 16th month, and reached the lowest point in the 20th month. The lowest speed was lower than that in the 6th month. The main reason is that the heading face is getting closer to anomaly area 3 in 4 and 16 
TABLE 2: Simulation model weight assignment.

\begin{tabular}{|c|c|c|}
\hline Index & $W_{j}$ & Weight value \\
\hline Influence of geological structure level of heading face on heading speed & $W_{1}$ & 0.3176 \\
\hline Influence of working environment level of heading face on heading speed & $W_{2}$ & 0.3175 \\
\hline Influence of normal level of heading face on heading speed & $W_{3}^{2}$ & 0.123 \\
\hline Influence of starting level of heading face on heading speed & $W_{4}$ & 0.123 \\
\hline Influence of mechanical equipment fault level coal mining on heading face speed in heading face & $W_{5}$ & 0.1189 \\
\hline Mine pressure level of heading face & $W_{6}$ & 0.3008 \\
\hline Gas level of heading face & $W_{7}^{0}$ & 0.4901 \\
\hline Mine water level of heading face & $W_{8}$ & 0.2091 \\
\hline Roof breakage degree of heading roadway & $W_{9}^{8}$ & 0.4012 \\
\hline Roof subsidence level of heading face & $W_{10}$ & 0.2908 \\
\hline Approaching level of two sides of tunneling roadway & $W_{11}^{10}$ & 0.308 \\
\hline Influence of geological structure level on advancing speed of coal mining face & $W_{12}$ & 0.2986 \\
\hline Influence of working environment level of coal mining face on advancing speed of working face & $W_{13}$ & 0.1962 \\
\hline Influence of the normal level of the working face on the advancing speed of the working face & $W_{14}$ & 0.0616 \\
\hline Influence of mining face level on working face advancing speed & $W_{15}^{14}$ & 0.0792 \\
\hline Influence of mechanical equipment failure level of coal mining on working face advancing speed & $W_{16}$ & 0.0835 \\
\hline Influence of roadway end management level on working face advancing speed & $W_{17}^{10}$ & 0.099 \\
\hline Influence of driving speed on advancing speed of working face & $W_{18}^{11}$ & 0.1819 \\
\hline Mine pressure level of coal mining face & $W_{19}^{10}$ & 0.3325 \\
\hline Gas level in coal mining face & $W_{20}$ & 0.5278 \\
\hline Mine water level of coal mining face & $W_{21}$ & 0.1397 \\
\hline Roof breakage degree of coal mining face & $W_{22}^{21}$ & 0.3062 \\
\hline Roof subsidence level of coal mining face & $W_{23}^{22}$ & 0.3012 \\
\hline Roof deformation level of coal mining face & $W_{24}^{23}$ & 0.3926 \\
\hline Roadway advanced support level & $W_{25}^{2 t}$ & 0.35 \\
\hline The approaching level of two sides of roadway & $W_{26}^{20}$ & 0.65 \\
\hline
\end{tabular}

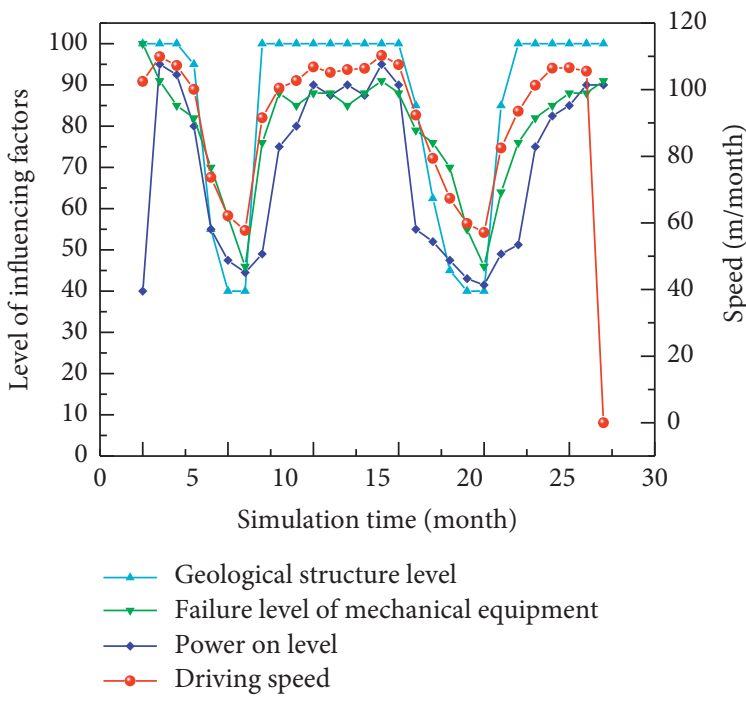

(a)

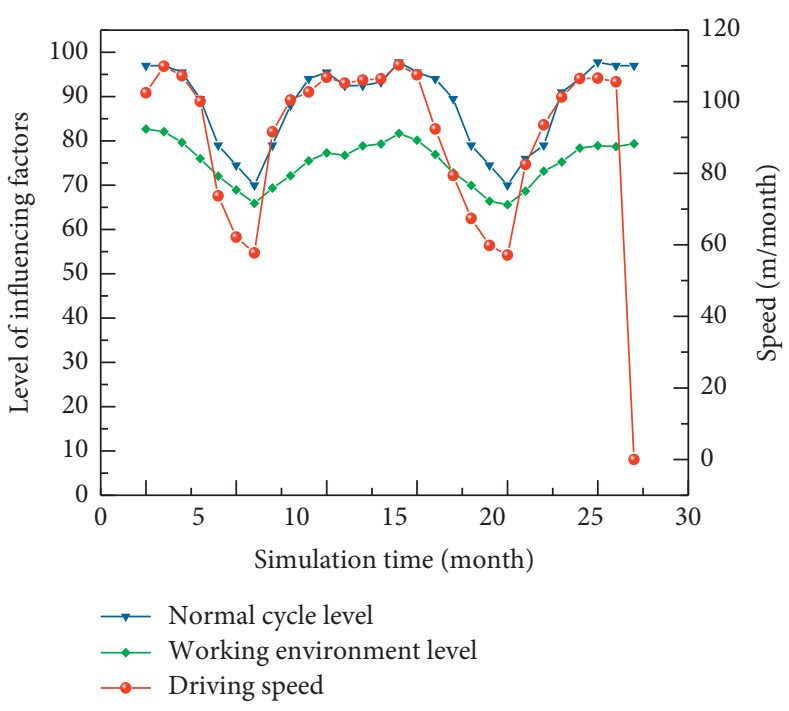

(b)

FIGURE 3: Relationship between driving speed and influencing factors.

months, and the return air roadway traverses the anomaly area, so it has a greater influence on it. As a result, the driving speed is lower and the duration is longer in the 20th month, thus affecting the normal replacement between roadway driving. The driving footage is the cumulative amount of the driving speed. According to the driving footage curve, it can also be seen that the trend of the driving footage curve becomes slow in the month with a lower driving speed. It can be seen from Figure 5(c) that under normal circumstances, the driving speed is lower than the advancing speed of the working face, and it has a certain impact on the advancing speed of the working face. The trends are not exactly the same because the advancing speed of working face is also affected by other factors. Figure 5(d) shows that the 

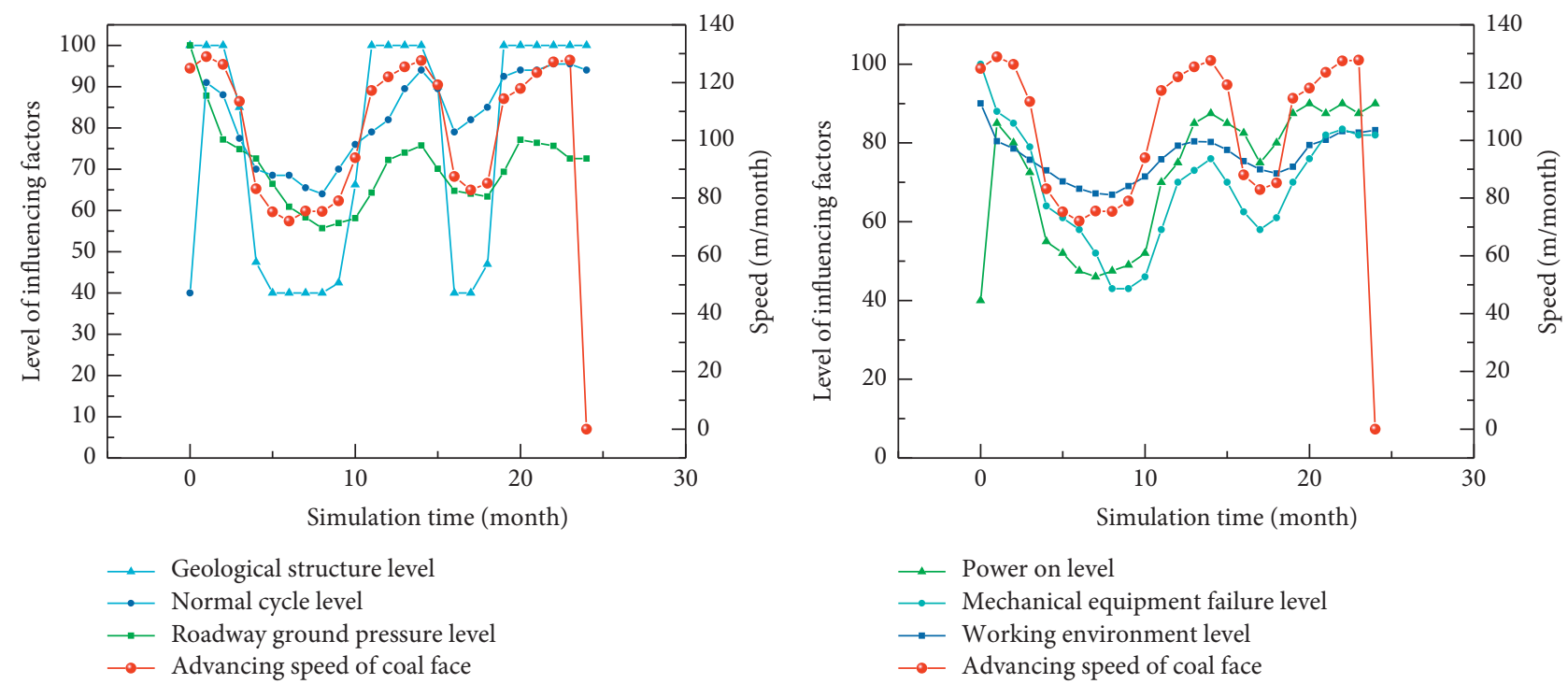

(a)

(b)

FIgURE 4: Relationship between the level of each influencing factor and the advancing speed of coal mining face.
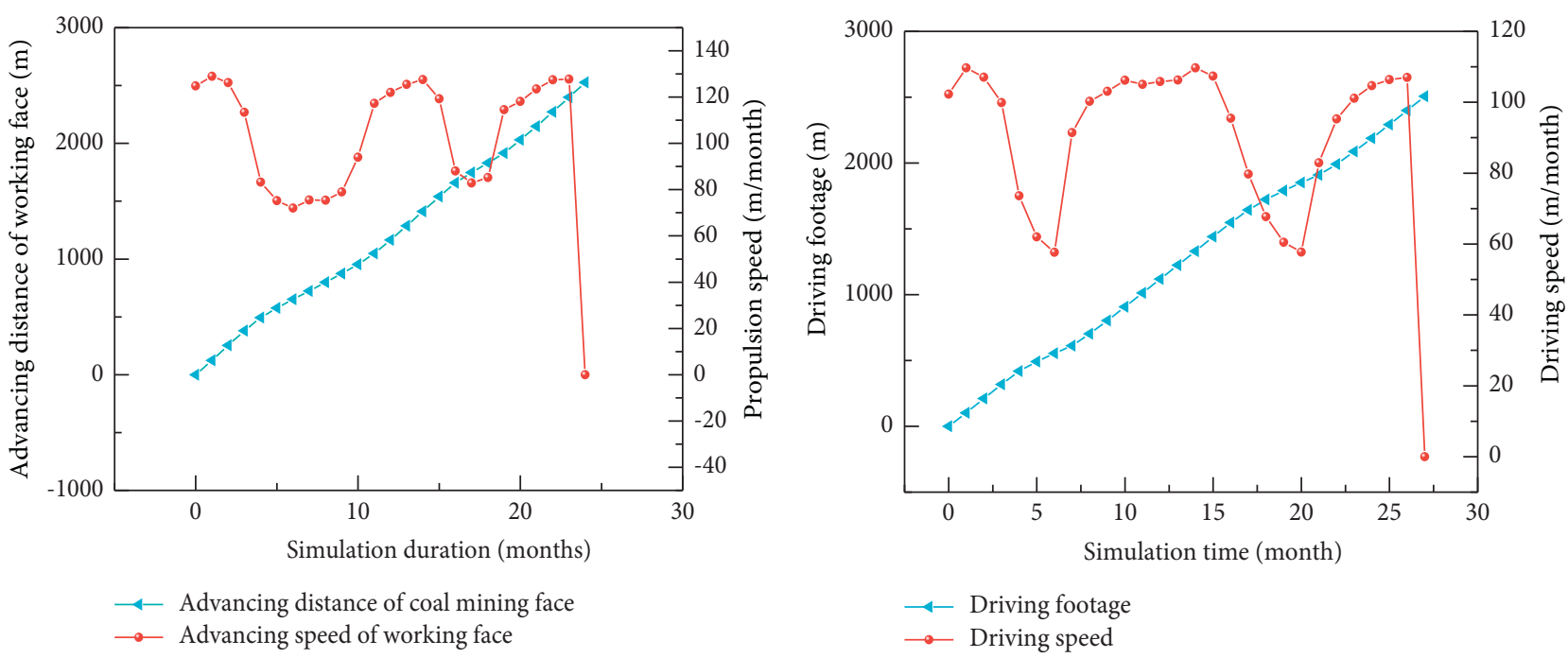

4- Advancing distance of coal mining face

$\rightarrow$ Advancing speed of working face

(b)

(a)

Figure 5: Continued. 


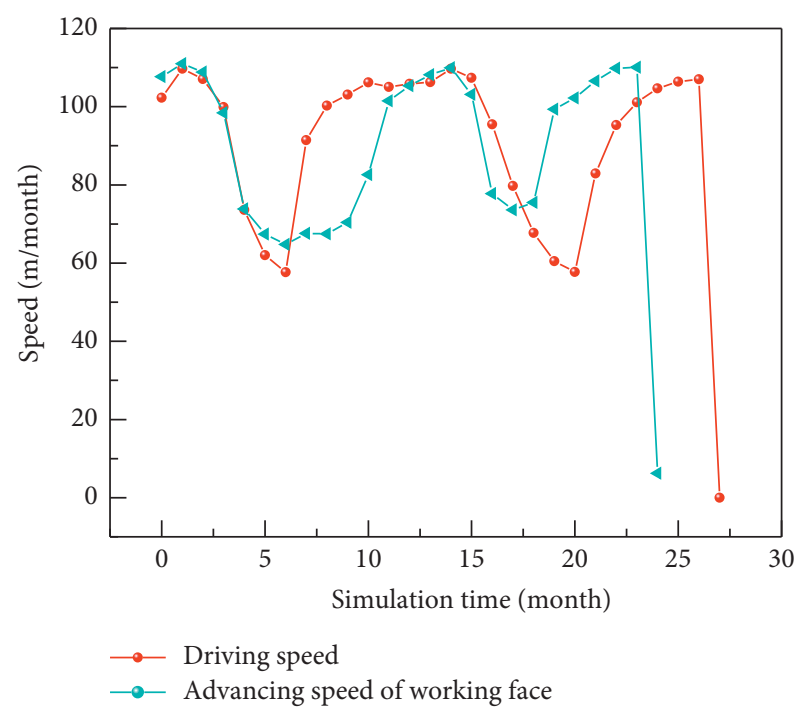

(c)

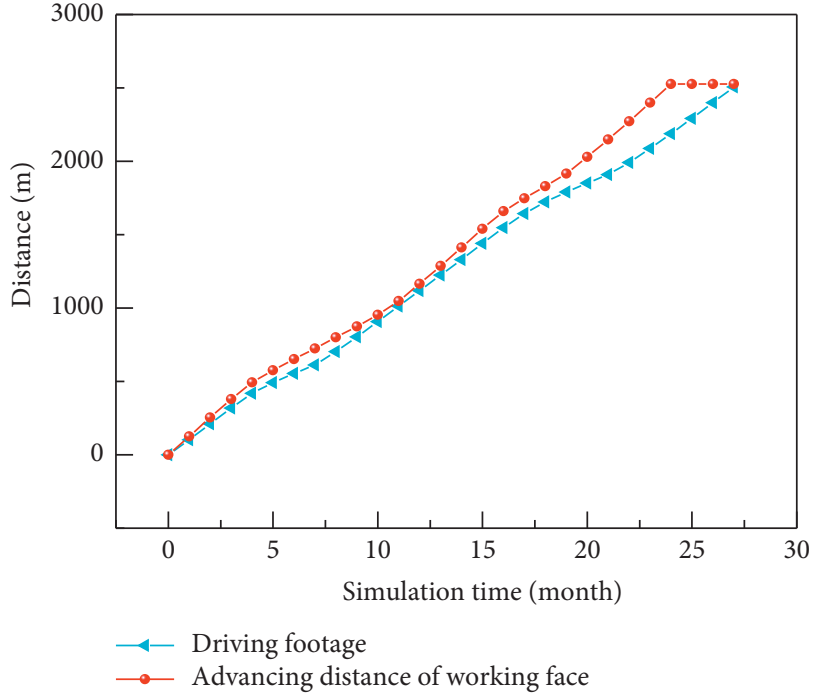

(d)

FIGURE 5: Simulation results of mining-driving system: (a) relationship between advancing speed and advancing distance of working face; (b) relationship between driving speed and driving footage; (c) relationship between driving footage and advancing distance of working face; (d) relationship between driving speed and advancing speed of working face.

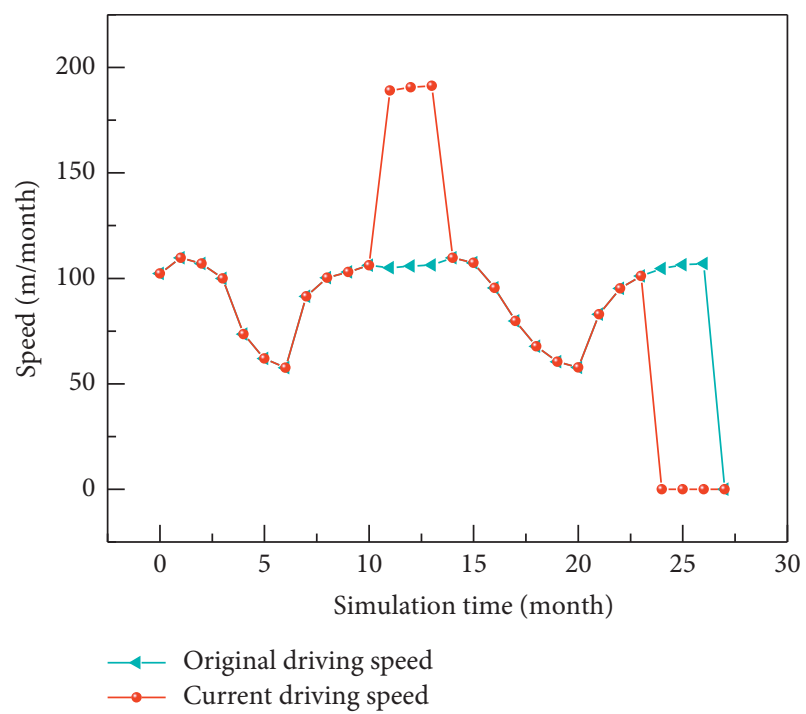

(a)

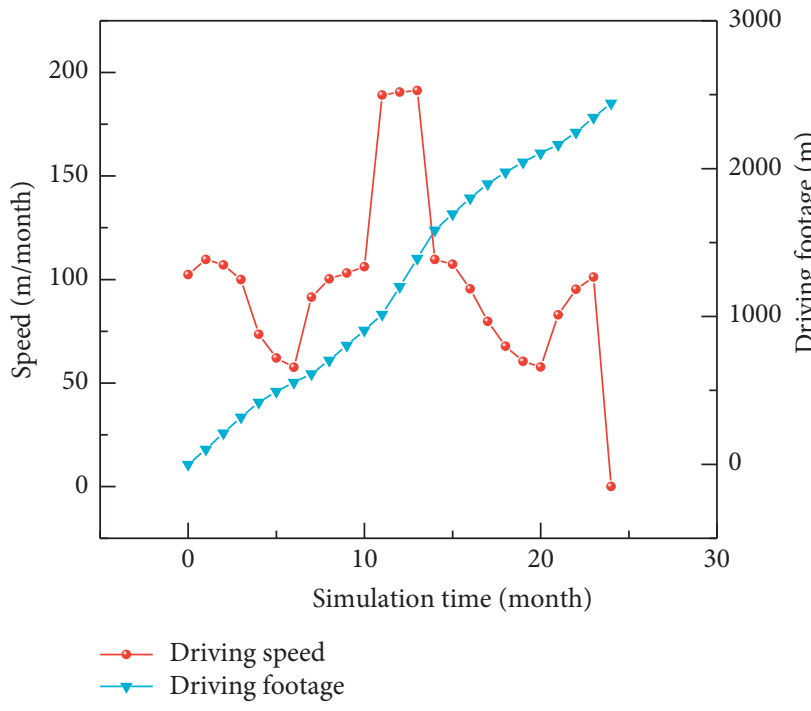

(b)

Figure 6: Continued. 


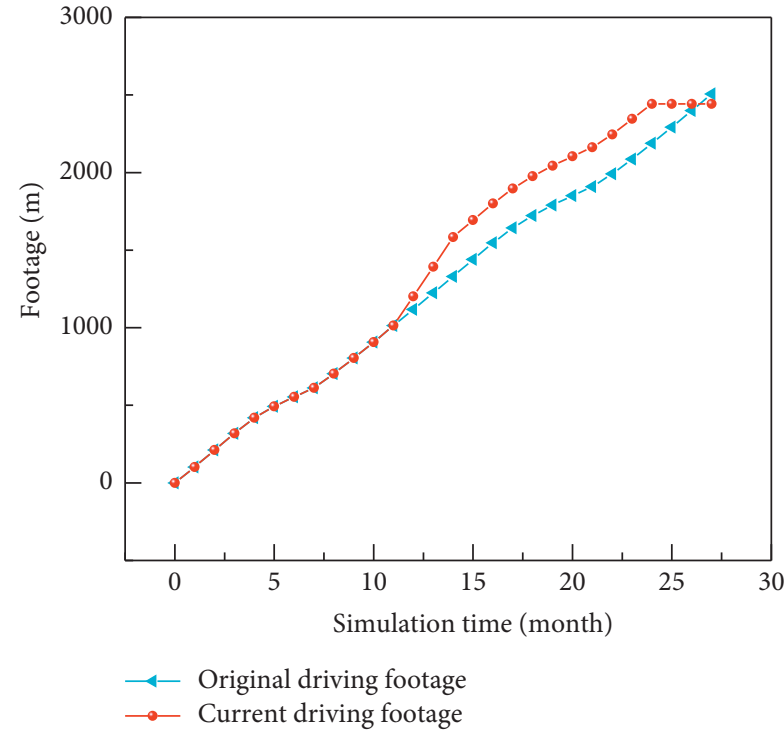

(c)

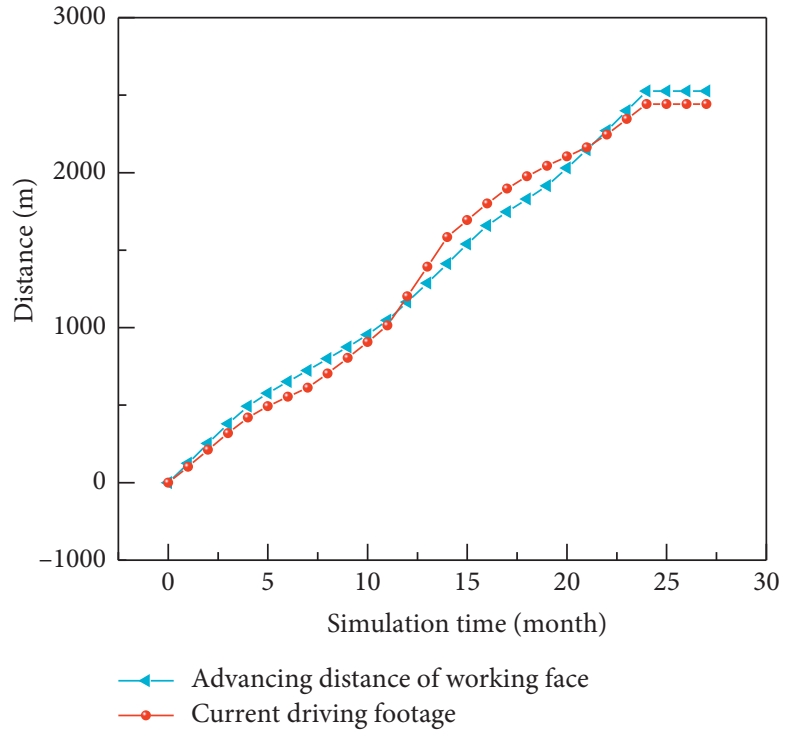

(d)

FIGURE 6: Simulation results of mining plan arrangement: (a) relationship between original driving speed and current driving speed; (b) relationship between current driving speed and driving footage; (c) relationship between original driving footage and current driving footage; (d) relationship between working face advancing distance and current driving footage.

fully mechanized mining team completed the entire construction period in the 24th month, while the tunneling team completed the entire construction period in the 27th month, which is 3 months later than the mining face, and there is an imbalance problem between mining and driving.

\subsection{The Optimization of Mining and Driving Replacement.} It can be seen from the simulation results that there is an imbalance problem in the replacement of mining and driving. Due to the relatively complicated process of the tunneling face itself, the normal driving speed is relatively slow. Secondly, the tunneling face encountered anomaly area 3 in the 4 th and 16th months, which affected the normal driving speed. For the reason that most of the factors affecting the driving speed are the changes of geological conditions, resulting in the change of other factors, and most of them belong to the mine hydrogeological factors, it is difficult to improve the driving speed by changing these factors. In order to ensure the balance of mining replacement, the following two aspects can be considered.

(1) Advance tunneling period: from Figure 5(d), it can be seen that the coal mining team completes the construction period 3 months earlier than the tunneling team. If the tunneling team starts working three months earlier, the construction period will be completed at the same time as the mining team to ensure the normal replacement of mining.

(2) Arranging more tunneling teams at the right time: when the resources are sufficient, two driving teams can be reasonably arranged to work. The tunneling working face is composed of transport lane and return air lane, and the two roadways do not affect each other when working, which can meet the requirements of two tunneling teams working at the same time. Through further simulation, the paper found that in the 11th month, a new driving team was added to start work in the transport lane, and the two teams worked in parallel from 11 to 13 months, and after the 13th month (return air lane driving task is completed), the remaining roadway driving tasks are completed independently by the second team. The specific simulation results are shown in Figure 6.

It can be seen from Figure 6(a) that in the 11th month, due to the simultaneous operation of the two teams, the driving speed has increased significantly. After the 13th month, since only one team is operating, the driving speed has dropped to the original level. It can be seen from Figure 6(b) that at the current driving speed, the driving team's driving footage reached 2,441.765 meters in the 24th month, which is still nearly 60 meters away from completing the task. However, after the completion of the construction period, the working face will take time to move. Therefore, it has basically completed the driving task. Figure 6(c) shows that the improved driving plan completes the task 3 months earlier than the original plan. Figure 6(d) shows that the replacement of mining and driving has basically worked properly.

\section{Conclusions}

Based on the system dynamics modeling, the dynamic simulation structure model of mining-driving system in Wangzhuang Mine was established with the help of Vensim software, and the dynamic simulation of 9102 mining face and 7106 heading face was carried out. The results show that 
there exists the phenomenon of replacement imbalance between mining and driving. Advancing the driving schedule or adding a new driving team can meet the demand of normal replacement. It can provide guidance for making driving and mining planning in other similar working faces. Optimizing the driving process reasonably helps to realize the perfect coordination of mining face and roadway driving in time and avoid the emergence of mining face replacement tension and resource waste phenomenon, which ensures the mine efficiency and production safety to the utmost extent.

\section{Data Availability}

All data and models used to support the findings of this study are included within the article.

\section{Conflicts of Interest}

The authors declare that they have no conflicts of interest.

\section{Acknowledgments}

The authors acknowledge the financial support provided by the National Key Research and Development Plan (grant no. 2017YFC1503103).

\section{References}

[1] G. F. Wang, F. Liu, X. J. Meng, J. D. Fan, and Q. Y. Wu, "Research and practice of coal mine intelligence (primary stage)," Coal Science and Technology, vol. 47, no. 8, pp. 1-36, 2019.

[2] D. Z. Kong, S. J. Pu, Z. H. Cheng, G. Wu, and Y. Liu, "Coordinated deformation mechanism of the top coal and filling body of gob-side entry retaining in a fully mechanized caving face," International Journal of Geomechanics, vol. 21, no. $4,2021$.

[3] S. H. Zhang, Dynamic Simulation and Optimization of Mining Replacement and Ventilation System in Outburst Mine, China University of Mining, Xuzhou, China, 2012.

[4] H. Wang, "Development of comprehensive mechanized tunneling technology in China 40a," Journal of China Coal Society, vol. 35, no. 11, pp. 1815-1820, 2010.

[5] S. Yang, X. Z. Hua, P. Yang, and X. Liu, Determination and Engineering Practice of Unsupported Roof Distance for Rapid Excavation of Roadway with Thick and Hard Basic Roof, (prepublish), Geotechnical and Geological Engineering, Netherlands, Europe, 2021.

[6] Y. Chen, Y. Zhang, J. Y. Geng, and F. T. Wang, "Process optimization and support technology of integrated rapid excavation of high-stress coal roadway with driving and anchoring," Coal mine safety, vol. 50, no. 7, pp. 120-123, 2019.

[7] Z. G. Zhang, "Development trend and key technology of coal roadway rapid excavation system," Coal Science and Technology, vol. 44, no. 01, pp. 55-60, 2016.

[8] A. Arabaninezhad and A. Fakher, "A practical method for rapid assessment of reliability in deep excavation projects," Iranian Journal of Science and Technology, Transactions of Civil Engineering, vol. 45, 2020.

[9] Y. D. Liu, J. Lin., J. W. Yang, and P. F. Jiang, "Rapid excavation and support technology of extra-thick top coal roadway based on the integration of driving and anchoring," Coal Science and Technology, vol. 45, no. 10, pp. 60-65, 2017.
[10] J. F. Lou, F. Q. Gao, J. H. Yang et al., "Characteristics of evolution of mining-induced stress field in the longwall panel: insights from physical modeling," International Journal of Coal Science Technology, vol. 20, no. 8, pp. 15-26, 2021.

[11] Y. F. Yan, Research on Coal Mine Tunneling Replacement Network Model and Reasoning System, Taiyuan University of Technology, Taiyuan, China, 2017.

[12] Z. M. Tian, Research and Design of Intelligent Decision Support System for Mine Excavation Replacement, Hebei University of Engineering, Handan, China, 2014.

[13] Y. J. Yuan, Y. Tian, and J. Sun., "System dynamics modeling and simulation of the stability of industry-university-research technology alliance," Science of Science and Science and Technology Management, vol. 34, no. 4, pp. 3-9, 2013.

[14] Y. W. Jia and L. M. Jia, "The construction of system dynamics model for sustainable development of high-tech enterprises in universities," Research and Development Management, vol. 26, no. 3, pp. 97-103, 2014.

[15] M. Wu, Analysis of Land Use Carbon Emissions and System Dynamics Simulation in Wuhan City, Huazhong Agricultural University, Wuhan, China, 2017.

[16] G. He, System Analysis of Coal Mine Safety Influencing Factors and Research on System Dynamics Simulation, Anhui University of Science and Technology, Huainan, China, 2009.

[17] B. Zhang, Z. H. Yu, Q. Sun, S. Li, M. X. Huang, and L. Q. Wang, "Environment and sustainable development," Introduction to System Dynamics and Summary of Related Software, vol. 35, no. 2, pp. 1-4, 2010.

[18] J. B. Chen, J. Z. Zhong, and B. S. Xie, "Research on system dynamics simulation of building materials supply chain," Journal of Physics: Conference Series, vol. 1864, no. 4, 2021.

[19] J. J. Wang, Q. Guo, F. Wang, K. B. Aviso, R. R. Tan, and X. Jia, "System dynamics simulation for park-wide environmental pollution liability insurance," Resources, Conservation and Recycling, vol. 170, 2021.

[20] L. Mai and Y. Song, "Research on traffic congestion based on system dynamics," Car practical technology, vol. 46, no. 4, pp. 29-30+65, 2021. 